\title{
Article \\ Hydrothermal Synthesis of Biphasic Calcium Phosphate from Cuttlebone Assisted by the Biosurfactant L-rhamnose Monohydrate for Biomedical Materials
}

\author{
Thamonwan Tattanon ${ }^{1}$, Premjit Arpornmaeklong ${ }^{2}$, Sarute Ummartyotin ${ }^{1, *}$ and Thirawudh Pongprayoon ${ }^{3,4, *}$ \\ 1 Department of Materials and Textile Technology, Faculty of Science and Technology, Thammasat University, \\ Patumtani 12120, Thailand; bua.2540@hotmail.com \\ 2 Department of Tissue Engineering and Implant Dentistry, Thammasat University, Patumtani 12120, Thailand; \\ apremjit@tu.ac.th \\ 3 Department of Chemical Engineering, Faculty of Engineering, King Mongkut's University of Technology \\ North Bangkok, Bangkok 10800, Thailand \\ 4 Center of Eco-Materials and Cleaner Technology, King Mongkut's University of Technology North Bangkok, \\ Bangkok 10800, Thailand \\ * Correspondence: sarute@tu.ac.th (S.U.); thirawudh.p@eng.kmutnb.ac.th (T.P.)
}

\section{check for}

updates

Citation: Tattanon, T.; Arpornmaeklong P.; Ummartyotin, S.; Pongprayoon, T. Hydrothermal Synthesis of Biphasic Calcium Phosphate from Cuttlebone Assisted by the Biosurfactant L-rhamnose Monohydrate for Biomedical Materials. ChemEngineering 2021, 5, 88. https://doi.org/10.3390/ chemengineering 5040088

Academic Editors: Andrew S. Paluch and Alírio E. Rodrigues

Received: 2 November 2021

Accepted: 8 December 2021

Published: 16 December 2021

Publisher's Note: MDPI stays neutral with regard to jurisdictional claims in published maps and institutional affiliations.

Copyright: (c) 2021 by the authors. Licensee MDPI, Basel, Switzerland. This article is an open access article distributed under the terms and conditions of the Creative Commons Attribution (CC BY) license (https:/ / creativecommons.org/licenses/by/ $4.0 /)$.

\begin{abstract}
The motivation of this research work is to develop novel medical material from cuttlebone (calcium source) by L-rhamnose monohydrate (biosurfactant) for aged people. The process can be synthesized biphasic calcium phosphate which is eco-friendly to environment. One of the most important aspects for this work is to use cuttlebone as a naturally occurring calcium source from a local beach in Thailand. It usually contains $90 \%$ calcium carbonate. The objective of this research work is to synthesize the biphasic calcium phosphate by hydrothermal reaction. Critical micelle concentrations (CMCs) of 10, 20, 100, 500 and 1000 of L-rhamnose monohydrate were used to control particle size and shape. XRD revealed a mixture of $\beta$-tricalcium phosphate and hydroxyapatite powder. SEM reported that the size of particles can be effectively controlled by the addition of L-rhamnose monohydrate, and with the addition of surfactant, size uniformity was achieved. The cytotoxicity test was reported to be in the range of 70-75\%. It was remarkable to note that biphasic calcium phosphate synthesized from cuttlebone with the aid of L-rhamnose monohydrate will be considered an excellent candidate as a scaffold material.
\end{abstract}

Keywords: biphasic calcium phosphate; cuttlebone; L-rhamnose monohydrate; surfactant-assisted hydrothermal; biosurfactant; biomaterials

\section{Introduction}

Currently, an aging society exists, which is typically defined as the fraction of older people in the entire population reaching $20 \%$ [1]. With the exponential increase in elderly people, the demand for health care is consequently growing. One of the most important issues for older people is bone deterioration. As a result, the repair of bone is difficult to maintain when injured. Moreover, the expenditure of health care monitoring is relatively high; therefore, for lower- and middle-income countries, access is limited.

The development of biobased materials has been evident until the present time. Numerous types of biomaterials have been improved from naturally occurring and synthetic routes. The utilization of biomaterials has been strongly employed in various research sectors, such as medical devices, pharmaceutical technology and dental materials. Among those, the development of biomaterials in medical research has been favorable. It is remarkable to note that the role of biomaterials is to support, enhance and replace damaged tissue. The advantage of biomaterials is related to environmental safety, nontoxicity to cells and excellent biocompatibility. The use of biomaterials was therefore encouraged due to naturally occurring resources and abundant availability [2,3]. Furthermore, the use 
of biomaterials was strongly encouraged by the "green policy" $[4,5]$. This was related to the product and process through which hazardous material should be preferably avoided. To date, biomaterials can be categorized into many distinct classes, and they were typically related to cellulose, chitin-chitosan, polylactic acid and hydroxyapatite. One of the most attractive biomaterials is hydroxyapatite. It was structurally defined as a naturally occurring mineral from calcium apatite with an empirical formula of $\mathrm{Ca}_{10}\left(\mathrm{PO}_{4}\right)_{6}(\mathrm{OH})_{2}$. This illustrated a stoichiometric $\mathrm{Ca} / \mathrm{P}$ ratio of 1.67 [6]. It provides many benefits, such as biocompatibility, biodegradability and dimensional stability in specific environments [7]. Although hydroxyapatite provides numerous advantages in terms of environmental concern, it is still limited in particular areas of medical use. One of the important concerns was relevant to its solubility in particular cell media. Furthermore, hydroxyapatite is directly destroyed by cells during the cell proliferation step [8]. With variation of the morphology, the difficulty of solubility occurred. This reduced the efficiency of hydroxyapatite when it was further employed as a scaffold. To overcome this issue, biphasic calcium phosphate between hydroxyapatite and $\beta$-tricalcium phosphate was successfully prepared. From a fundamental point of view, biphasic calcium phosphate was considered a mixture of powder between hydroxyapatite and $\beta$-tricalcium phosphate. $\beta$-tricalcium phosphate was defined as a calcium salt of phosphoric acid with an empirical formula of $\mathrm{Ca}_{3}\left(\mathrm{PO}_{4}\right)_{2}$ [9]. It was environmentally friendly and showed excellent solubility and chemical stability. The existence of $\beta$-tricalcium phosphate in hydroxyapatite can significantly provide excellent solubility and perfect adherence during the cell proliferation step. In medical research, the existence of tricalcium phosphate can provide $\mathrm{Ca}^{2+}$ ions. It can induce osteoconductivity when employed as a scaffold material [10].

In 2015, Shavandi et al. [11] developed nanosized hydroxyapatite from waste mussel shells. The uniformity in size and shape can be controlled to be less than $100 \mathrm{~nm}$. Notably, the microwave-assisted method enhanced the rate of HA formation. Furthermore, nanosized hydroxyapatite was successfully prepared from waste kina shells (Evechinus chloroticus). The product provided high porosity, and the interconnected structure was preserved. No toxicity to osteoblast cells was observed [12]. In 2018, Ofudje et al. [13] developed hydroxyapatite powder by using waste pig bones as a raw material. The product offered a high porosity of up to $55 \%$, which made it attractive for use in tissue engineering applications. Thus, it was remarkable that the chemical reagent for hydroxyapatite synthesis was typically related to $\mathrm{CaCO}_{3}$. One of the most readily available naturally occurring resources is cuttlebone [14].

Cuttlebone is theoretically defined as an internal shell found in all members of the family Sepiidae. It is composed of $80-90 \mathrm{wt} . \% \mathrm{CaCO}_{3}$. It offers high compressive strength, high porosity and high permeability [15]. It is commonly employed in the lime prediction and jewelry making industry. In addition, the utilization of cuttlebone was strongly encouraged by the blue economic policy, which was theoretically related to a framework of sustainable marine activity and marine-based technologies. Furthermore, to utilize cuttlebone with higher efficiency, it was considered as a raw material to synthesize biphasic calcium phosphate [16].

Recently, in 2020, Kangkan et al. developed $\beta$-tricalcium phosphate powder from cuttlebone by a hydrothermal reactor. The size and shape were successfully controlled by the presence of the anionic surfactant sodium dodecyl sulfate (SDS) [17]. This surfactant has a negative charge on its hydrophilic end. It can support molecular lift and suspend soils in micelles. It is commonly employed in the soap and detergent industries. From the viewpoint of nanomaterial synthesis, an anionic surfactant was utilized during the synthetic step for size and shape control. This process is commonly used in heterogeneous catalysts, Portland cement and the removal of hazardous metal ions.

In contrast, although anionic surfactants from petroleum bases provide numerous advantages, they are still limited due to environmental concerns as they are difficult to decompose when employed in large-scale commercial production. To overcome this issue, the use of biosurfactants is considered one of the best alternative routes. From 
the viewpoint of biotechnologists, biosurfactants can be derived from living organisms (bacteria, yeast and fungi). The structure of the biosurfactant is identical to that of the surfactant. However, it provides many benefits, such as biodegradability, nontoxicity and biocompatibility. Moreover, the use of biosurfactant illustrated a stable reaction. It is easy to employ various types of chemical reagents in the process [18]. To date, L-rhamnose monohydrate is commonly employed as a biosurfactant. It is structurally defined as a glycolipid in which one or two molecules of rhamnose are linked to one or two molecules of hydroxy decanoic acid [19]. Furthermore, L-rhamnose monohydrate is commonly available due to the presence of the sugar industry, as it can be found in sugarcane bagasse [20].

The new finding of this work is the use of biosurfactants to synthesize biphasic calcium phosphate and to control the nanostructure and phase of particles. Moreover, biphasic calcium phosphate synthesized with biosurfactants will be employed in biomedical applications with biocompatibility and nontoxicity for human use. In this work, we wish to develop biphasic calcium phosphate by hydrothermal synthesis. Cuttlebone and Lrhamnose monohydrate were employed as a raw material and biosurfactant, respectively. Investigation of the structural, morphological and specific surface area of biphasic calcium phosphate was reported, and the preliminary test of the cytotoxicity was presented.

\section{Materials and Methods}

\subsection{Materials}

Cuttlebone from the collection on the Thailand beach was used as the raw material to synthesize biphasic calcium phosphate. Phosphoric acid $\left(158^{\circ} \mathrm{C}\right.$ boiling point and $42{ }^{\circ} \mathrm{C}$ melting point) was purchased from $\mathrm{Q}$ Chemical Co., Ltd. (Bangkok Thailand). Ammonium hydroxide $\left(38^{\circ} \mathrm{C}\right.$ boiling point and $-58^{\circ} \mathrm{C}$ melting point) was purchased from MACRON Chemicals Co., Ltd. (Valenzuela, Philippines). Phosphoric acid and ammonium hydroxide were the analytical grade reagents, employed as reactants and solvents to synthesize particles. L-rhamnose monohydrate (batch No. RB-20190725, with $324^{\circ} \mathrm{C}$ boiling point and $90^{\circ} \mathrm{C}$ melting point) was purchased from Xi'an Rainbow Biotech Co., Ltd. (Xi'an, China). It was employed as a biosurfactant template. All analytical grade chemicals were used without further purification.

\subsection{Methods}

2.2.1. Synthesis of Biphasic Calcium Phosphate from Cuttlebone by a Surfactant-Assisted Hydrothermal Process

Briefly, the impurity in cuttlebone was certainly removed by washing with DI water several times. The washed cuttlebone was dried in an oven at $90{ }^{\circ} \mathrm{C}$ for $3 \mathrm{~h}$ to vaporize contaminates and odor. Then, it was milled into a small particle for calcination in a furnace at $700{ }^{\circ} \mathrm{C}$ for $4 \mathrm{~h}$. The calcined particle was completely dissolved in $50 \mathrm{~mL}$ of DI water. Then, phosphoric acid was added into the solution. After that, various amounts of L-rhamnose monohydrate (critical micelle concentrations (CMCs) of 10, 20, 100, 500 and 1000) were added to the solution. The solution was controlled to have a $\mathrm{pH}$ of 9 by ammonium hydroxide. Then, it was placed into a Teflon lined stainless steel autoclave. The reaction of the hydrothermal process was isothermally conducted at $60{ }^{\circ} \mathrm{C}$ for $2 \mathrm{~h}$. After that, the synthesized particle was washed with DI water several times until a neutral $\mathrm{pH}$ was achieved. Then, it was calcined at $700{ }^{\circ} \mathrm{C}$ for $4 \mathrm{~h}$. The powder should be stored in desiccator. A schematic diagram of $\beta$-tricalcium phosphate synthesized by a hydrothermal reactor with a variation in the critical micelle concentration of L-rhamnose monohydrate is reported in Figure 1.

\subsubsection{Characterization}

Fourier Transform Infrared Spectroscopy (FTIR)

The FTIR spectra of the investigated samples were recorded with a Nicolet Impact 410 FTIR. A diamond crystal was employed as the reflection element. The spectra were 
measured in the spectral range from 4000 to $400 \mathrm{~cm}^{-1}$ with the operation of $\pm 4 \mathrm{~cm}^{-1}$ resolution and 32 times scan frequency. The measurement was run at room temperature.

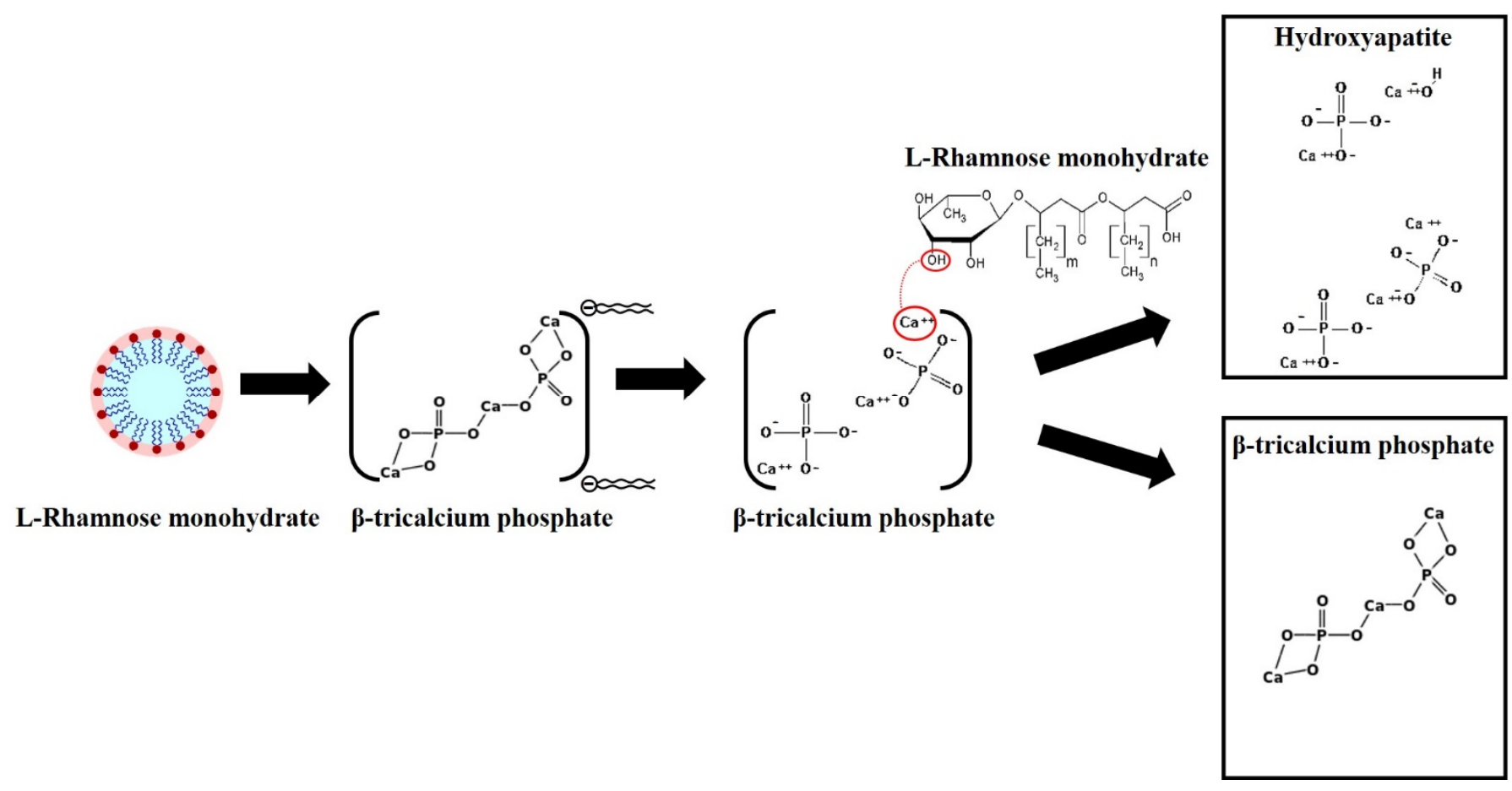

Figure 1. Schematic diagram of biphasic calcium phosphate synthesized by a hydrothermal reaction using L-rhamnose monohydrate as a biosurfactant.

\section{X-ray Diffraction}

The crystal structure of the synthesized calcium phosphate was analyzed by XRD (Phillips P.W. 1830 diffractometer) with nickel filtered $\mathrm{CuK} \alpha$ radiation. The peaks corresponded to hydroxyapatite and $\beta$-tricalcium phosphate in accordance with JCPDS No. 00064-0738 and JCPDS No. 09-0169, respectively, of the ICDD standard (the International Centre for Diffraction Data) [21]. Diffraction patterns were recorded over a range of 20-60 . Scherrer equation was used to calculate the crystallite size.

The Scherrer equation:

$$
\tau=\frac{K \lambda}{\beta \operatorname{Cos} \theta}
$$

where

$\tau$ refers to the crystallite size,

$K$ is the dimensionless shape factor,

$\lambda$ is the $\mathrm{X}$-ray wavelength,

$\beta$ is the live boarding at half the maximum intensity (FWHM),

$\theta$ is the Bragg angle.

\section{Scanning Electron Microscopy}

SEM (Quanta 250 SEM microscope, Japan) was used to observe the morphology of the synthesized calcium phosphate. Before SEM observation, the specimens were goldcoated with a sputtering device (Jeol, JFC-1200). Magnification and accelerating voltages of $30,000 \mathrm{X}$ and $5 \mathrm{kV}$ were selected. The particle size of the samples was evaluated by an ImageJ software. 
Dynamic Light Scattering (DLS)

Dynamic light scattering (Malvern Instruments; Model 4700) were performed as a light scattering with an argon laser source at the wavelength of $520 \mathrm{~nm}$. The measurements were made at $90^{\circ}$ of a scattering angle, with a $200 \mathrm{~mm}$ pinhole for the homodyne intensityintensity correlation. The sample was measured as the colloid of the particle suspended in solution. It can be a single particle or agglomerate, depending on the dispersity of the colloid and the charge of the solvent.

\section{BET Analysis}

The $\mathrm{N}_{2}$ adsorption-desorption analyzer (Quantrachome, Autosorb IQC) was employed for the BET analysis to measure the surface area, pore size and pore volume of the investigated particles. A total 10-mg investigated particles were inserted into the equipment. The samples were pretreated to vaporize moisture for the allowance of $\mathrm{N}_{2}$ absorption at $-196{ }^{\circ} \mathrm{C}$. The sample was degassed under vacuum at $250{ }^{\circ} \mathrm{C}$ for $8 \mathrm{~h}$ before the measurement.

\section{Zeta Potential}

The zeta potential of the particles was analyzed by using Nanopartica SZ-100, Horiba. The sample was prepared by dispersing the investigated particles in DI water. The duration time of $50 \mathrm{~s}$ and scanning number of 10 were set for measurement.

\subsubsection{Cytotoxicity Test}

The cytotoxicity test was investigated in accordance with the MTT cytotoxicity assay (ISO 10993-5). The tissue code was L929 (mouse fibroblast cells, ATCC CCL1, NCTC 929, of strain L). Briefly, a cell suspension of $1 \times 10^{5}$ cells $/ \mathrm{mL}$ L929 in medium was seeded into a 96-well plate. The cells were incubated at $37 \pm 1{ }^{\circ} \mathrm{C}, 5 \pm 0.1 \% \mathrm{CO}_{2}$ and $95 \pm 5 \%$ relative humidity for $24 \pm 2 \mathrm{~h}$ to obtain confluent monolayers of cells prior to testing. Thermanox coverslips and polyurethane films consisting of $0.1 \%$ zinc diethyldithiocarbamate were employed as a negative control and a positive control, respectively. The mass-to-volume extraction ratio was adjusted to $0.1 \mathrm{~g} / \mathrm{mL}$. After incubation, the viable cells were stained with MTT (3-(4,5-dimethyl thiosol-2-yl)-2,5-diphenyltetrazolium bromide) and incubated further for $2 \mathrm{~h}$. After that, MTT was removed, DMSO was added to each well and the absorbance using a microplate reader was measured at $570 \mathrm{~nm}$.

\section{Results and Discussion}

Biphasic calcium phosphate was successfully synthesized from cuttlebone as the biomaterial precursor. All samples typically presented as a white fine powder. The powder became agglomerated, and thus it should be kept in a desiccator to protect moisture adsorption. With a high critical micelle concentration of L-rhamnose monohydrate under the hydrothermal method, the powder became fine.

Figure 2 exhibits the FTIR spectra of biphasic calcium phosphate with variation in the CMC. The characteristic peaks at wavenumbers of 588 and $1003 \mathrm{~cm}^{-1}$ were attributed to $\mathrm{P}-\mathrm{O}$ stretching and $\mathrm{P}-\mathrm{O}$ bending, respectively. This referred to $\mathrm{PO}_{4}{ }^{3-}$ of hydroxyapatite and the $\beta$-tricalcium phosphate structure. Compared to the other peaks, the intensity is broad, suggesting that the purity of the product was high. Additionally, the characteristic peaks at wavenumbers of 3570 and $728 \mathrm{~cm}^{-1}$ were related to $\mathrm{O}-\mathrm{H}$ stretching in the hydroxyapatite structure. Other possibilities were due to the adsorption of humidity on the powder surface. All of the characteristic peaks were in agreement with previous results reported by Khiri et al. [22]. The characteristic peak at $1455 \mathrm{~cm}^{-1}$ corresponded to $\mathrm{C}=\mathrm{O}$ stretching. This is due to the presence of the carbonyl group of L-rhamnose monohydrate and cuttlebone. This was associated with the previous work of Wan et al. [23]. However, with increasing calcination temperature, the intensity is lower. The carbonyl group disappeared due to the removal of L-rhamnose monohydrate and cuttlebone. The reduction in intensity was related to the fact that L-rhamnose monohydrate was changed to gaseous oxide at higher 
temperatures, as suggested by Ghosh et al. [24]. It can be implied that the calcination step was used to purify the biphasic calcium phosphate product.

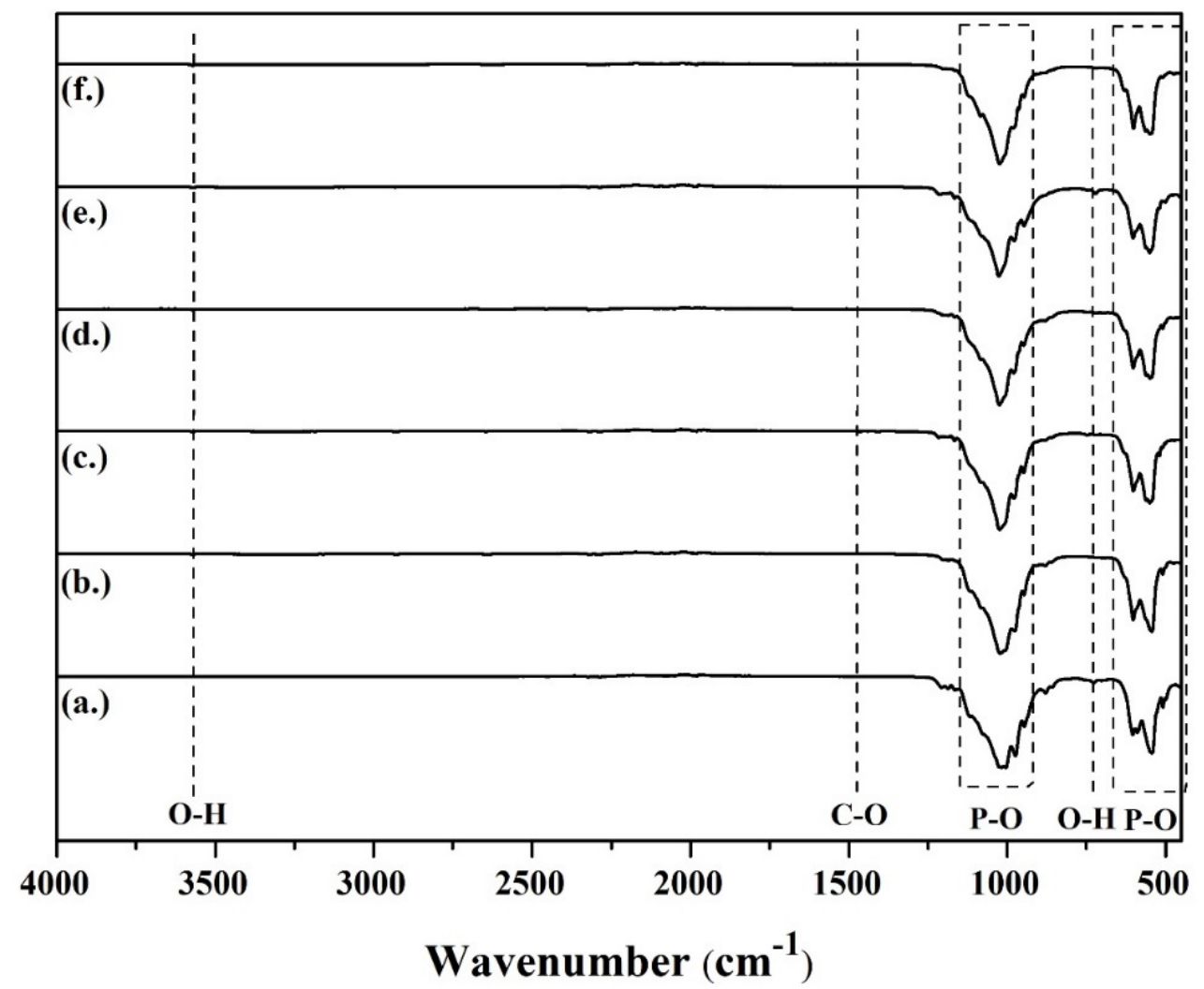

Figure 2. FTIR spectra of biphasic calcium phosphate prepared by cuttlebone with variation of the CMC of L-rhamnose monohydrate biosurfactant: (a) no CMC, (b) $10 \mathrm{CMC}$, (c) $20 \mathrm{CMC}$, (d) $100 \mathrm{CMC}$, (e) $500 \mathrm{CMC}$ and (f) $1000 \mathrm{CMC}$.

Figure 3 presents the XRD patterns of biphasic calcium phosphate with a variation in the CMC of L-rhamnose monohydrate. Without L-rhamnose monohydrate, a single phase of $\beta$-tricalcium phosphate was successfully synthesized. The characteristic peaks at $2 \theta$ values of $28^{\circ}, 31^{\circ}, 35^{\circ}$ and $53^{\circ}$ were presented. These peaks corresponded to Miller indices of (2 14$),(0210),\left(\begin{array}{lll}2 & 2 & 0\end{array}\right)$ and (2 0 20), respectively. This result was similar to the previous work of Kangkan et al. [17]. Furthermore, in the presence of L-rhamnose monohydrate, the biphasic phase between calcium phosphate and hydroxyapatite was synthesized. The role of L-rhamnose monohydrate can be induced by $\mathrm{OH}$ formation on the surface of calcium phosphate. The characteristic peaks at $26.0^{\circ}, 31.9^{\circ}, 32.3^{\circ}, 33.0^{\circ}, 39.9^{\circ}$, $41.8^{\circ}$ and $47.0^{\circ}$ were presented. These peaks corresponded to Miller indices of (102), (211), (112), (300), (130), (113) and (222), respectively. This result was similar to the previous work of Chandrasekar et al. [25]. Both hydroxyapatite and tricalcium phosphate peaks were in agreement with JCPDS No. 09-0169 and JCPDS No. 896438, respectively. With increasing $\mathrm{CMC}$, the intensity of hydroxyapatite became evident. It can be implied that the presence of a high amount of L-rhamnose monohydrate can significantly offer O-H adsorption onto the calcium phosphate surface.

However, quantitative analysis by XRD cannot estimate the ratio of the appeared phases. The intensity of peaks implied the quantity of phases. Notably, the intensity of characteristic peaks of tricalcium phosphate increased when the critical micelle concentration was increased. This is consistent with the previous work of Ebrahimi et al. [21].

Table 1 reports the crystallite size of biphasic calcium phosphate synthesized from cuttlebone. This method is similar to the previous work of Pinjari et al. [26]. All tests 
typically reported a crystallite size of $16-19 \mathrm{~nm}$. The variation in the CMC of L-rhamnose monohydrate did not affect the crystallite size.

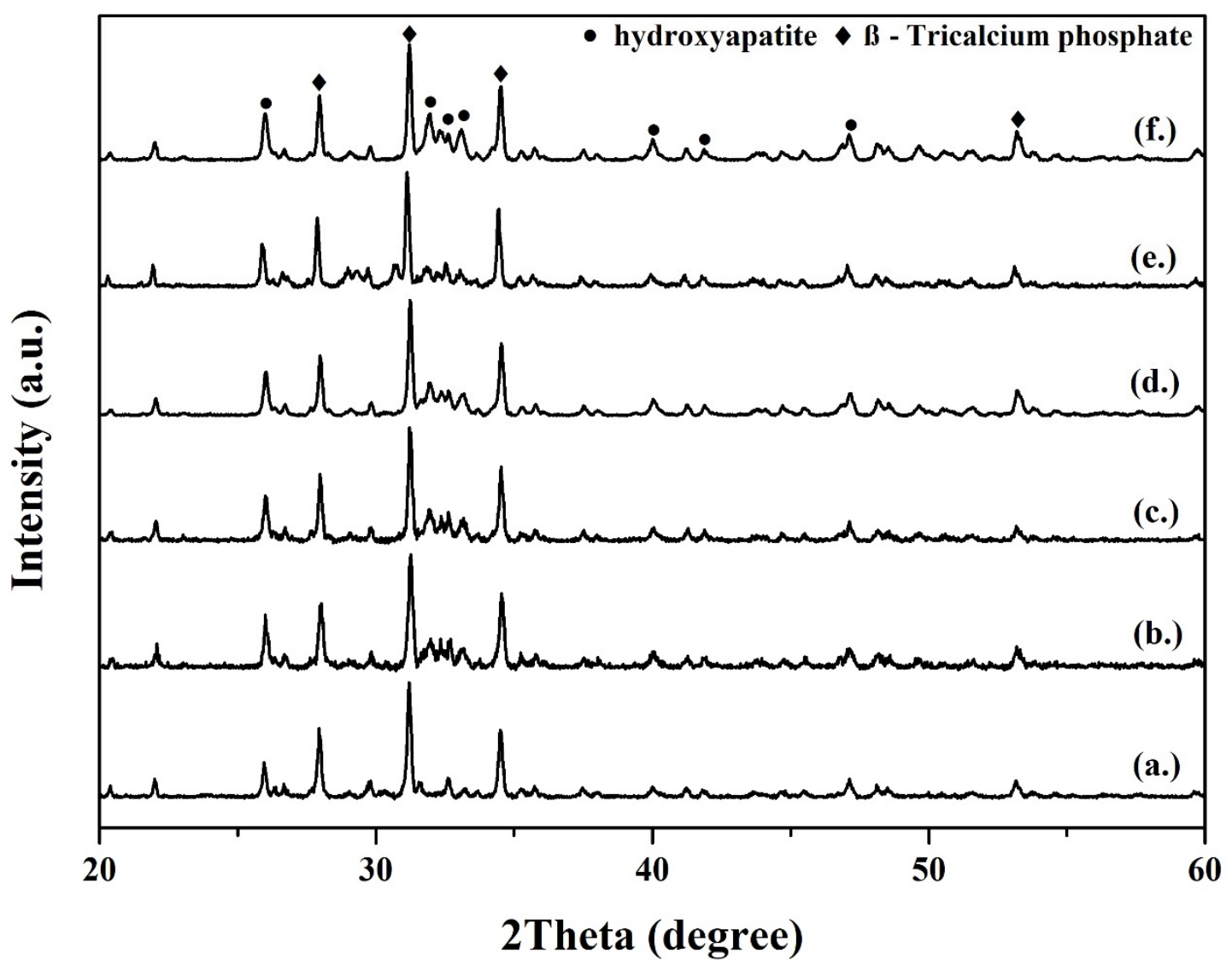

Figure 3. XRD pattern of biphasic calcium phosphate prepared by cuttlebone with variation of the CMC of L-rhamnose monohydrate biosurfactant: (a) no CMC, (b) 10 CMC, (c) 20 CMC, (d) 100 CMC, (e) 500 CMC and (f) 1000 CMC.

Table 1. Crystallite size of biphasic calcium phosphate prepared by cuttlebone with a variation of the CMC of L-rhamnose monohydrate biosurfactant.

\begin{tabular}{cc}
\hline CMC & Crystallite Size (nm) \\
\hline 0 & 16.8 \\
10 & 18.4 \\
20 & 18.5 \\
100 & 18.4 \\
500 & 18.4 \\
1000 & 18.4 \\
\hline
\end{tabular}

Figure 4 reports the scanning electron microstructure of biphasic calcium phosphate. All images present the typical morphology of biphasic calcium phosphate, reporting the particle size and porosity of the particles. The experiment without L-rhamnose monohydrate was provided for comparison. All of the particle shapes were nonuniform. The red arrow and blue arrow indicate the positions of the particle and porosity, respectively. Without L-rhamnose monohydrate, a large particle size was observed. The porosity was present between particles. On the other hand, with increasing CMC, the particle size significantly decreased. Notably, with a higher CMC of L-rhamnose monohydrate, it can create a "head-to-tail" structure surrounding biphasic calcium phosphate particles. A smaller size of particles was therefore observed. Furthermore, porosity occurred during the pyrolysis process. The L-rhamnose monohydrate, with an empirical formula of $\mathrm{C}_{6} \mathrm{H}_{12} \mathrm{O}_{5}$, 
was changed to volatile gas. The porosity is shown as a pathway of gas evaporation along biphasic calcium phosphate particles.

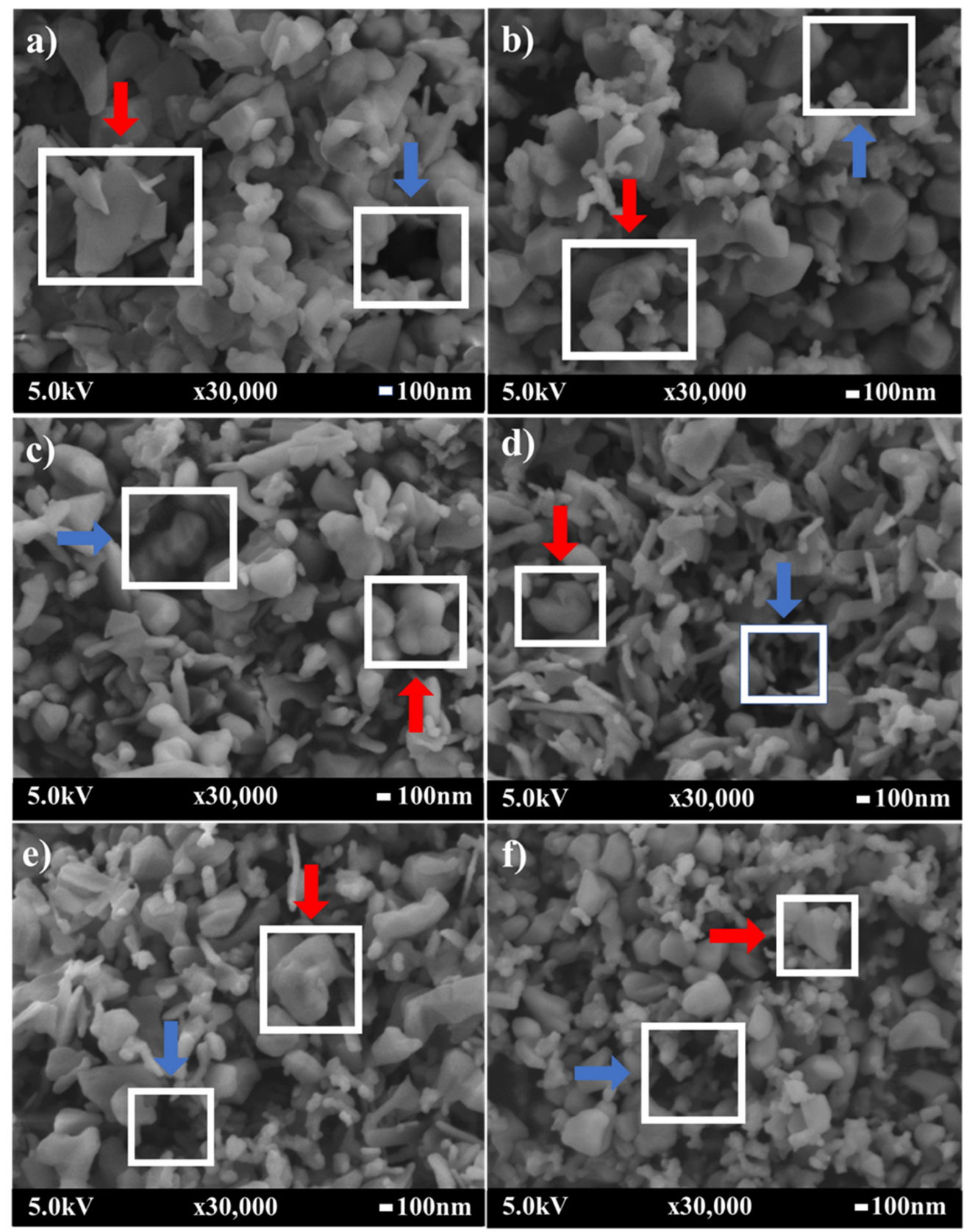

Figure 4. Morphological properties of biphasic calcium phosphate prepared by cuttlebone with variation of the CMC of L-rhamnose monohydrate biosurfactant: (a) no CMC, (b) $10 \mathrm{CMC}$, (c) $20 \mathrm{CMC}$, (d) $100 \mathrm{CMC}$, (e) $500 \mathrm{CMC}$ and (f) $1000 \mathrm{CMC}$.

Figure 5 reports the particle size analysis of biphasic calcium phosphate synthesized from cuttlebone. The particle size was analyzed by ImageJ software connected to SEM microstructure images. The experiment was conducted for 20 measurements per 1 SEM image. One hundred experiments were subsequently reported to ensure the statistical average. Single particles were observed. The experiment without L-rhamnose monohydrate was provided for comparison. Notably, without L-rhamnose monohydrate, a large variation in size was observed. The average and standard deviation of the particle size were 489.5 and $184.74 \mathrm{~nm}$, respectively. After that, when L-rhamnose monohydrate was poured into the mixture, the tendency of the particle size of biphasic calcium phosphate was smaller. 
Moreover, the range of standard deviation was also narrower. The uniform size of biphasic calcium phosphate was controlled by the head-to-tail structure of the biosurfactant during the reaction under a hydrothermal process. The average size and standard deviation of the particles were significantly reduced to $300-400$ and $80-120 \mathrm{~nm}$, respectively. These technical data were similar to the microstructural analysis with SEM images.
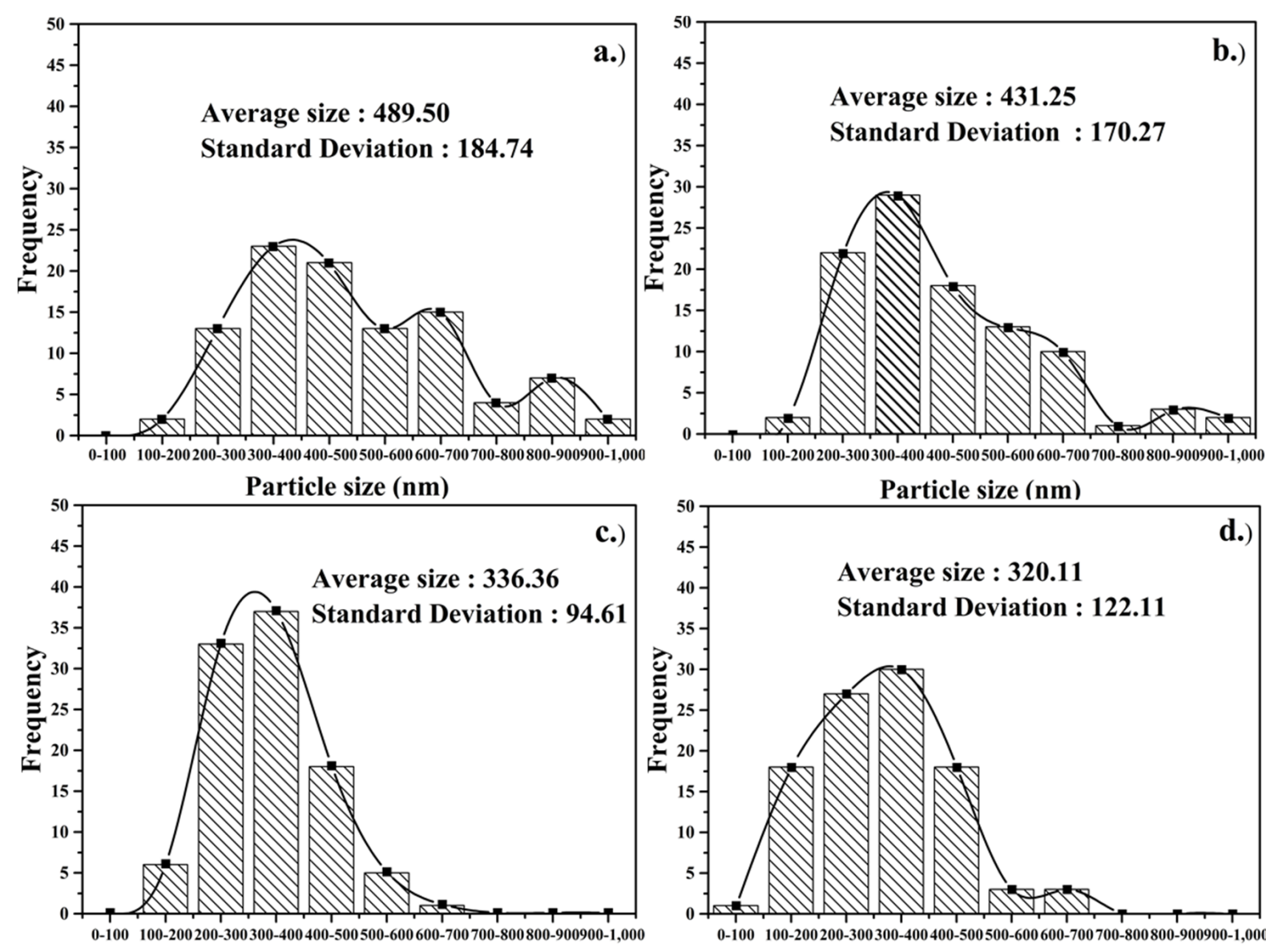

Particle size (nm)
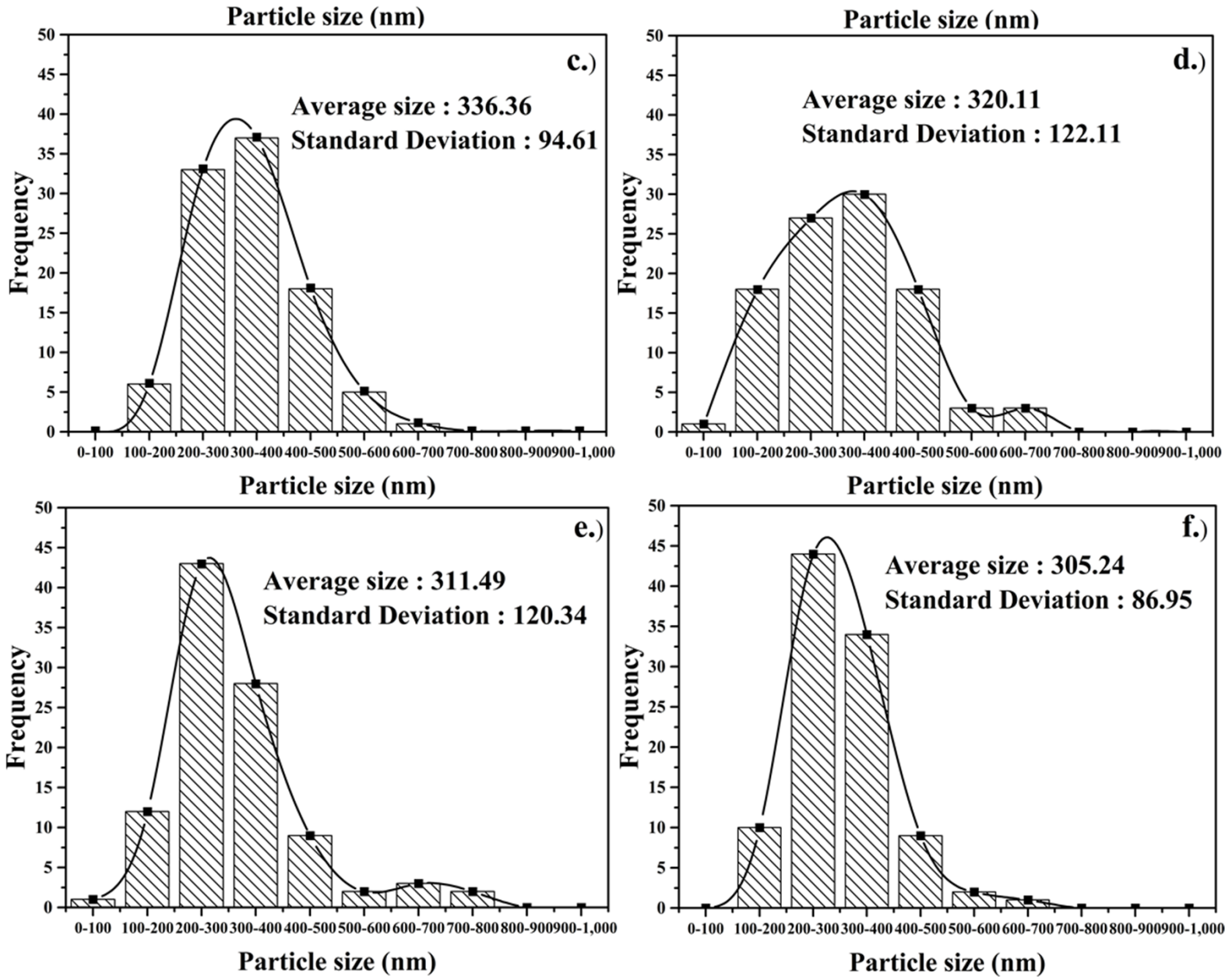

Figure 5. Particle size analysis of biphasic calcium phosphate prepared by cuttlebone with variation of the CMC of L-rhamnose monohydrate biosurfactant: (a) no CMC, (b) 10 CMC, (c) 20 CMC, (d) 100 CMC, (e) 500 CMC and (f) 1000 CMC.

The formula for average size and SD is also provided. 
Average size formula

$$
\text { Average }=\frac{\text { Total Sum of All Numbers }}{\text { Number of Item in the Set }}
$$

Standard deviation formula

$$
\sigma=\sqrt{\frac{1}{N} \sum_{i=1}^{N}\left(x_{i}-\mu\right)^{2}}
$$

- $\sigma=$ population standard deviation.

- $\mu=$ assumed mean.

Figure 6 reports the diameter of biphasic calcium phosphate synthesized by cuttlebone. It was notable that all of the samples reported particle sizes in the range of 500-1500 nm. It can be a single particle and/or particle agglomeration cluster, depending on the dispersity of the colloid and solvent. This result is similar to the previous work of Da Cruz et al. [27]. The variation in particle size is due to the starting material. Cuttlebone is considered a naturally occurring bioresource. It exhibited various morphologies, and there were still impurities during the synthetic step; therefore, a broad particle size range was observed. However, it was notable that a narrow size distribution can be effectively controlled by the CMC of L-rhamnose monohydrate. This was in agreement with the particle size analyzed by ImageJ software in Figure 5.

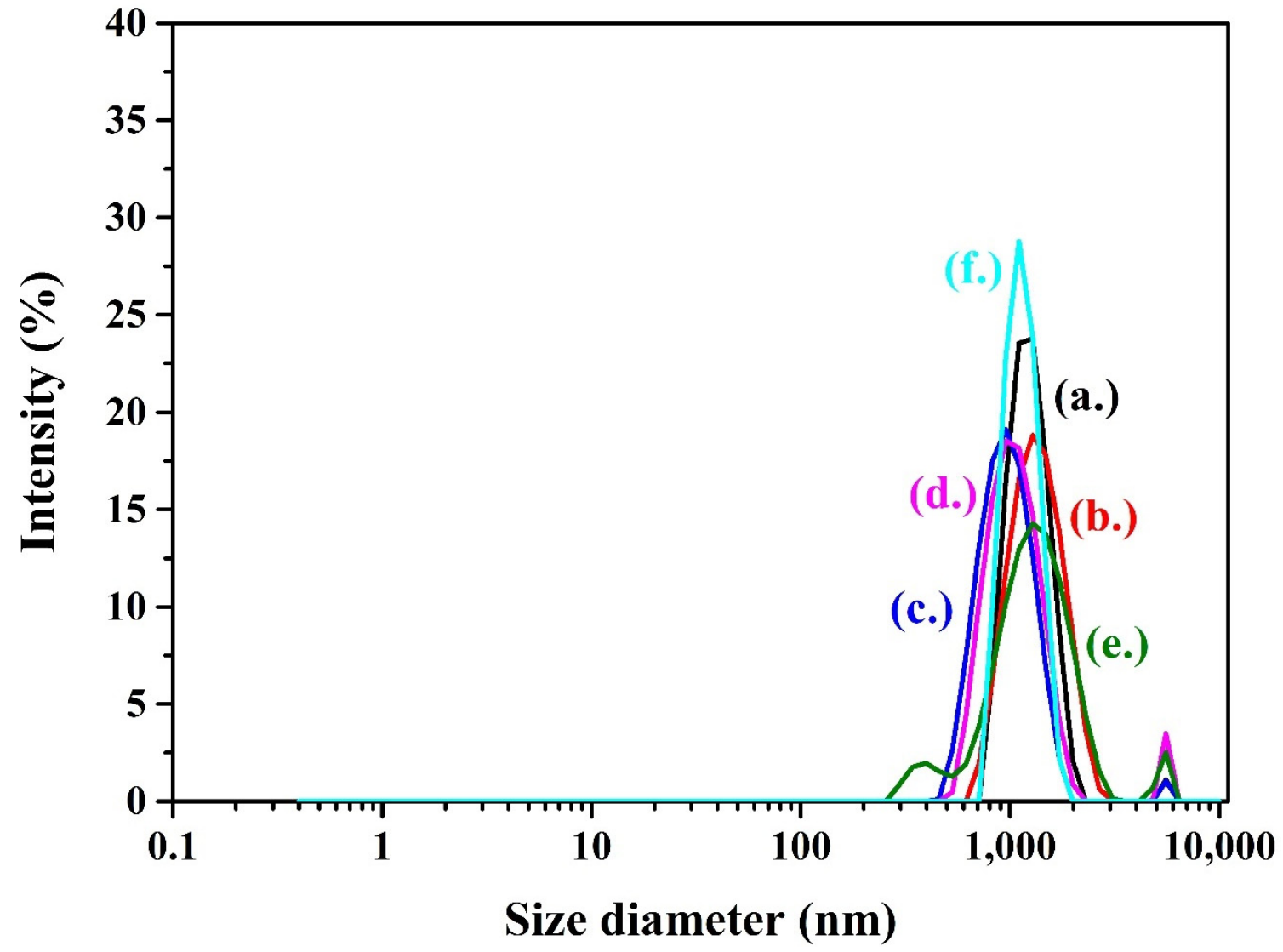

Figure 6. Size diameter analysis by dynamic light scattering (DLS) of biphasic calcium phosphate prepared by cuttlebone with variation of the CMC of L-rhamnose monohydrate biosurfactant: (a) no CMC, (b) 10 CMC, (c) 20 CMC, (d) 100 CMC, (e) $500 \mathrm{CMC}$ and (f) $1000 \mathrm{CMC}$. 
Three techniques were used to analyze the size of the particles. Table 1 and Figures 5 and 6 report the crystallite size by the Scherrer equation from XRD results, ImageJ analysis from the SEM microstructure and DLS results, respectively. The calculated size is the crystallite size, which is the smallest size grain in the particles. For SEM images, the ImageJ program was used to estimate the single particle or core particle size of the dried sample from SEM micrographs. It was typically larger than the crystallite size. In the case of DLS analysis, it is used to measure the size of colloids suspended in liquid, and the size is the colloid size, which may be a single particle or agglomerate, depending on the nature of the surface charge of the particle and solution. The size measured from this technique is equal to or larger than the size analyzed from the SEM image.

Table 2 presents the BET surface area, pore volume and pore radius of biphasic calcium phosphate synthesized by cuttlebone. The ranges of the specific surface area, pore volume and pore radius were reported to be $4-9 \mathrm{~m}^{2} / \mathrm{g}, 0.006-0.013 \mathrm{~cm}^{3} / \mathrm{g}$ and $5-7 \mathrm{~nm}$, respectively. It was notable that variation of the CMC did not lead to a significant change in the specific surface area, pore volume and pore radius. In the case of the specific surface area, the variation can occur due to the change in the stoichiometric composition of biphasic calcium phosphate, as suggested by Mansir et al. [28]. In the case of the pore radius and pore volume, this range was associated with the mesoporous region. It can be employed as a host for cell attachment. A small pore diameter can be used to indicate the roughness on the surface. It is attractive for cell attachment, as suggested by Xia et al. [29].

Table 2. BET analysis of biphasic calcium phosphate prepared by cuttlebone with variation of the CMC of L-rhamnose monohydrate biosurfactant.

\begin{tabular}{cccc}
\hline CMC & Specific Surface Area $\left(\mathbf{m}^{2} / \mathbf{g}\right)$ & Pore Volume $\mathbf{( \mathbf { c m } ^ { 3 } / \mathbf { g } )}$ & Pore Radius $(\mathbf{n m})$ \\
\hline 0 & 4.15 & 0.006 & 5.71 \\
10 & 6.26 & 0.009 & 5.72 \\
20 & 6.83 & 0.009 & 5.55 \\
100 & 6.04 & 0.009 & 5.76 \\
500 & 6.31 & 0.009 & 5.86 \\
1000 & 8.55 & 0.013 & 6.11 \\
\hline
\end{tabular}

Table 3 presents the zeta potential analysis of biphasic calcium phosphate synthesized by cuttlebone. The zeta potential was found to be in the range of -5 to $+5 \mathrm{mV}$, indicating that the biphasic calcium phosphate particles synthesized from the cuttlebone had particle suspension instability. Only small repulsion was observed. This provided the possibility of forming large particles, as suggested by Guzelsu [30].

Table 3. Zeta potential analysis of biphasic calcium phosphate prepared by cuttlebone with variation in the CMC of L-rhamnose monohydrate biosurfactant.

\begin{tabular}{cc}
\hline CMC & Zeta Potential $(\mathbf{m V})$ \\
\hline 0 & -1.35 \\
10 & -1.07 \\
20 & -0.85 \\
100 & -1.68 \\
500 & -1.22 \\
1000 & -1.51 \\
\hline
\end{tabular}

To evaluate the possibility of biphasic calcium phosphate as a scaffold material, an in vitro cytotoxicity test was performed. Table 4 reports the cytotoxicity of biphasic calcium phosphate by mouse osteoblasts. Notably, the presence of L-rhamnose monohydrate significantly reduced the viability of cells. The optical density (OD) was measured at $570 \mathrm{~nm}$. It was employed to evaluate the cytotoxic grade in this group associated with cell proliferation. The optical density of all samples was reported in the range of $0.40-0.63$. 
The percent viability dropped from 91 to $70-75 \%$ when various amounts of L-rhamnose monohydrate were integrated into the mixture during the hydrothermal reaction because the CMC of L-rhamnose monohydrate affected cell survival. Although the existence of Lrhamnose monohydrate significantly provided a controllable size and shape, hydrophobic properties on the surface of the particles were observed. In this regard, Rahimi et al. [31] reported the cytotoxicity to human breast cancer cells. The presence of surfactant could effectively inhibit the growth of cells. A similar observation was reported by Zhao [32]. It can be concluded that, to understand cell viability, the type of cell and medium of culture play an important role in this consideration. It would be better to evaluate the biphasic calcium phosphate synthesized with various amounts of surfactant and its cell viability. At present, more investigation is required to understand the mechanism by which biphasic calcium phosphate will be employed as a scaffold material.

Table 4. Percentage of cell viability using the MTT cytotoxicity assay.

\begin{tabular}{ccc}
\hline Sample & OD $\mathbf{5 7 0} \mathbf{~ n m}$ & \% Viability \\
\hline Blank & 0.621 & 100 \\
Negative control & 0.625 & 100 \\
Positive control & 0 & 0 \\
0 CMC & 0.570 & 91 \\
10 CMC & 0.459 & 74 \\
20 CMC & 0.466 & 75 \\
100 CMC & 0.469 & 75 \\
500 CMC & 0.460 & 74 \\
1000 CMC & 0.439 & 70 \\
\hline
\end{tabular}

\section{Conclusions}

Cuttlebone can be employed as a source of naturally occurring calcium for biphasic calcium phosphate synthesis. L-rhamnose monohydrate can be employed to control the size and shape of biphasic calcium phosphate particles during hydrothermal processes. A mixture of $\beta$-tricalcium phosphate and hydroxyapatite was successfully prepared. The zeta potential reported that instability of particles was observed. They can be significantly formed into large particles. Three techniques were used to analyze the size of the particles. When the size is analyzed by Scherrer equation from XRD results, the size calculated is the crystallite size that is the smallest size grained in the particles. For SEM image, the ImageJ program was used to estimate the single particle or core particle size of the dried sample from the SEM micrograph. Without L-rhamnose monohydrate, a large particle size was observed. The porosity was present between particles. On the other hand, with increasing $\mathrm{CMC}$, the particle size significantly decreased. The size from this analysis is the size of a single particle that is bigger than the crystallite size. Then, DLS is used to measure the size of colloid suspended in liquid and the size is the colloid size that may be a single particle or agglomerate, depending on the nature of the surface charge of particle and solution. The size measured from this technique is equal to or bigger than the size analyzed from the SEM image. Although the size and shape were controllable by L-rhamnose monohydrate, the cell viability was decreased to $70-75 \%$. To design biphasic calcium phosphate as a scaffold material, increasing development of the morphology with respect to the amount of L-rhamnose monohydrate and cell viability will be required for further improvement.

Author Contributions: T.T.: conceptualization, methodology; P.A.: validation; S.U.: writingoriginal draft, writing - review and editing, supervision, resources; T.P.: writing-original draft, writing-review and editing, supervision, resources. All authors have read and agreed to the published version of the manuscript.

Funding: The authors would like to thank the National Science and Technology Development and King Mongkut's University Technology, North Bangkok, code number KMUTNB-Basic R-64-05, for financial support. 
Institutional Review Board Statement: Not applicable.

Informed Consent Statement: Not applicable.

Data Availability Statement: Not applicable.

Acknowledgments: This work was supported by the Center of Eco-Materials and Cleaner Technology, King Mongkut's University of Technology, North Bangkok, and the Thammasat University Research Unit in Textile and Polymer Chemistry.

Conflicts of Interest: The authors declare no conflict of interest.

\section{References}

1. Population on 1 January by Broad Age Group and Sex [Internet]. Available online: http://appsso.eurostat.ec.europa.eu/nui/ show.do (accessed on 2 December 2021).

2. Wani, S.U.D.; Gautam, S.P.; Qadrie, Z.L.; Gangadharappa, H. Silk fibroin as a natural polymeric based bio-material for tissue engineering and drug delivery systems-A review. Int. J. Biol. Macromol. 2020, 163, 2145-2161. [CrossRef] [PubMed]

3. Pawelzik, P.; Carus, M.; Hotchkiss, J.; Narayan, R.; Selke, S.; Wellisch, M.; Weiss, M.; Wicke, B.; Patel, M. Critical aspects in the life cycle assessment (LCA) of bio-based materials-Reviewing methodologies and deriving recommendations. Resour. Conserv. Recycl. 2013, 73, 211-228. [CrossRef]

4. Ladu, L.; Blind, K. Overview of policies, standards and certifications supporting the European bio-based economy. Curr. Opin. Green Sustain. Chem. 2017, 8, 30-35. [CrossRef]

5. Ladu, L.; Morone, P. Holistic approach in the evaluation of the sustainability of bio-based products: An Integrated Assessment Tool. Sustain. Prod. Consum. 2021, 28, 911-924e6. [CrossRef]

6. Safronova, T.V.; Putlyaev, V.I.; Shekhirev, M.A.; Tretyakov, Y.D.; Kuznetsov, A.V.; Belyakov, A.V. Densification additives for hydroxyapatite ceramics. J. Eur. Ceram. Soc. 2009, 29, 1925-1932. [CrossRef]

7. Khalid, H.; Chaudhry, A.A. 4-Basics of hydroxyapatite-Structure, synthesis, properties, and clinical applications. In Handbook of Ionic Substituted Hydroxyapatites; Khan, A.S., Chaudhry, A.A., Eds.; Woodhead Publishing: Sawston, UK, 2020 ; pp. $85-115$.

8. Huang, L.-H.; Sun, X.-Y.; Ouyang, J.-M. Shape-dependent toxicity and mineralization of hydroxyapatite nanoparticles in A7R5 aortic smooth muscle cells. Sci. Rep. 2019, 9, 18979. [CrossRef] [PubMed]

9. Jamil, M.; Elouahli, A.; Khallok, H.; El Ouatli, B.; Hatim, Z. Characterization of $\beta$-tricalcium phosphate-clay mineral composite obtained by sintering powder of apatitic calcium phosphate and montmorillonite. Surf. Interfaces 2019, 17, 100380. [CrossRef]

10. Liu, B.; Lun, D.-X. Current Application of $\beta$-tricalcium Phosphate Composites in Orthopaedics. Orthop. Surg. 2012, 4, 139-144. [CrossRef] [PubMed]

11. Shavandi, A.; Bekhit, A.E.-D.; Ali, A.; Sun, Z. Synthesis of nano-hydroxyapatite (nHA) from waste mussel shells using a rapid microwave method. Mater. Chem. Phys. 2015, 149-150, 607-616. [CrossRef]

12. Shavandi, A.; Wilton, V.; Bekhit, A.E.-D.A. Synthesis of macro and micro porous hydroxyapatite (HA) structure from waste kina (Evechinus chloroticus) shells. J. Taiwan Inst. Chem. Eng. 2016, 65, 437-443. [CrossRef]

13. Ofudje, E.A.; Rajendran, A.; Adeogun, A.I.; Idowu, M.A.; Kareem, S.O.; Pattanayak, D.K. Synthesis of organic derived hydroxyapatite scaffold from pig bone waste for tissue engineering applications. Adv. Powder Technol. 2018, 29, 1-8. [CrossRef]

14. Ferro, A.C.; Guedes, M. Mechanochemical synthesis of hydroxyapatite using cuttlefish bone and chicken eggshell as calcium precursors. Mater. Sci. Eng. C 2019, 97, 124-140. [CrossRef] [PubMed]

15. Checa, A.G.; Cartwright, J.; Sánchez-Almazo, I.; Andrade, J.; Ruiz-Raya, F. The cuttlefish Sepia officinalis (Sepiidae, Cephalopoda) constructs cuttlebone from a liquid-crystal precursor. Sci. Rep. 2015, 5, 11513. [CrossRef] [PubMed]

16. Kangkan, S.; Arpornmaeklong, P.; Ummartyotin, S. Synthesis of hydroxyapatite from cuttlebone under various pH conditions: An approach for medical materials. J. Metals Mater. Miner. 2020, 30, 136-141.

17. Kangkan, S.; Pongprayoon, T.; Ummartyotin, S. Morphologically controlled synthesis of ( $\beta$-tricalcium phosphate) $\beta$-TCP particles from cuttlebone by sodium dodecyl sulfate (SDS) anionic surfactant: In vitro behavior of mouse osteoblast cells. J. Mater. Res. Technol. 2020, 9, 3121-3127. [CrossRef]

18. Cameotra, S.S.; Makkar, R.S.; Kaur, J.; Mehta, S.K. Synthesis of Biosurfactants and Their Advantages to Microorganisms and Mankind. Adv. Exp. Med. Biol. 2010, 672, 261-280. [CrossRef]

19. Vijayakuma, S.; Varatharajan, S. Biosurfactants-Types, Sources and Applications. Res. J. Microbiol. 2015, 10, 181-192.

20. Tan, Y.N.; Li, Q. Microbial production of rhamnolipids using sugars as carbon sources. Microb. Cell Fact. 2018, 17, 89. [CrossRef] [PubMed]

21. Ebrahimi, M.; Botelho, M.G.; Dorozhkin, S.V. Biphasic calcium phosphates bioceramics (HA/TCP): Concept, physicochemical properties and the impact of standardization of study protocols in biomaterials research. Mater. Sci. Eng. C 2017, 71, 1293-1312. [CrossRef] [PubMed]

22. Khiri, M.Z.A.; Matori, K.A.; Zaid, M.H.M.; Abdullah, C.A.C.; Zainuddin, N.; Alibe, I.M.; Rahman, N.A.A.; Wahab, S.A.A.; Azman, A.Z.K.; Effendy, N. Crystallization behavior of low-cost biphasic hydroxyapatite/ $\beta$-tricalcium phosphate ceramic at high sintering temperatures derived from high potential calcium waste sources. Results Phys. 2019, 12, 638-644. [CrossRef] 
23. Wan, J.; Zeng, G.; Huang, D.; Hu, L.; Xu, P.; Huang, C.; Deng, R.; Xue, W.; Lai, C.; Zhou, C.; et al. Rhamnolipid stabilized nano-chlorapatite: Synthesis and enhancement effect on Pb-and Cd-immobilization in polluted sediment. J. Hazard. Mater. 2018 343, 332-339. [CrossRef] [PubMed]

24. Ghosh, R.; Sarkar, R. Synthesis and characterization of sintered beta-tricalcium phosphate: A comparative study on the effect of preparation route. Mater. Sci. Eng. C 2016, 67, 345-352. [CrossRef] [PubMed]

25. Chandrasekaran, A.; Suresh, S.; Dakshanamoorthy, A. Synthesis and characterization of nano-hydroxyapatite (n-HAP) using the wet chemical technique. Int. J. Phys. Sci. 2013, 8, 1639-1645.

26. Pinjari, D.V.; Pandit, A.B. Room temperature synthesis of crystalline $\mathrm{CeO}_{2}$ nanopowder: Advantage of sonochemical method over conventional method. Ultrason. Sonochem. 2011, 18, 1118-1123. [CrossRef] [PubMed]

27. Da Cruz, J.A.; Weinand, W.R.; Neto, A.M.; Palácios, R.S.; Sales, A.J.M.; Prezas, P.R.; Costa, A.A.; Graça, M.P.F. Low-Cost Hydroxyapatite Powders from Tilapia Fish. JOM 2020, 72, 1435-1442. [CrossRef]

28. Mansir, N.; Teo, S.; Ibrahim, M.L.; Hin, T.-Y.Y. Synthesis and application of waste egg shell derived CaO supported W-Mo mixed oxide catalysts for FAME production from waste cooking oil: Effect of stoichiometry. Energy Convers. Manag. 2017, 151, 216-226. [CrossRef]

29. Xia, J.; Yuan, Y.; Wu, H.; Huang, Y.; Weitz, D.A. Decoupling the effects of nanopore size and surface roughness on the attachment, spreading and differentiation of bone marrow-derived stem cells. Biomaterials 2020, 248, 120014. [CrossRef]

30. Guzelsu, N.; Wienstien, C.; Kotha, S. A new streaming potential chamber for zeta potential measurements of particles. Rev. Sci. Instrum. 2010, 81, 015106. [CrossRef]

31. Rahimi, K.; Lotfabad, T.B.; Jabeen, F.; Ganji, S.M. Cytotoxic effects of mono- and di-rhamnolipids from Pseudomonas aeruginosa MR01 on MCF-7 human breast cancer cells. Colloids Surf. B Biointerfaces 2019, 181, 943-952. [CrossRef] [PubMed]

32. Zhao, J.; Wu, Y.; Alfred, A.T.; Xin, X.; Yang, S. Chemical structures and biological activities of rhamnolipid biosurfactants produced by Pseudomonas aeruginosa M14808. J. Chem. Pharm. Res. 2013, 5, 177-182. 